\title{
THE ASSOCIATION BETWEEN HUMAN PAPILLOMA VIRUS AND LARYNGEAL MASSES
}

\author{
Ali Taleb Abdulsamad ${ }^{\circledR}$, Saad Abdulbaki ${ }^{*}$, Haider MS Al-Attar ${ }^{* *}, \&$ \\ Isam Alshareda ${ }^{\#}$ \\ ${ }^{\circledR}$ MB,ChB, FICMS Otolaryngology, Basrah Teaching Hospital. "MB,ChB, FICMS, Histopathology, \\ College of Medicine, University of Basrah. ${ }^{* *} \mathrm{MB}, \mathrm{ChB}$, FICMS Specialist Otolaryngologist, Basrah \\ Teaching Hospital, "MB,ChB, FICMS, Professor of Otolaryngology, Dept. of Surgery, College of \\ Medicine, University of Basrah, Basrah, IRAQ.
}

\begin{abstract}
The Human Papilloma Virus (HPV) can play a role in the development of head and neck tumors such as oropharyngeal tumors. Nevertheless, a real impact between Human Papilloma Virus and other head and neck sites such as the larynx is not well studied.

This study aimed to assess the association of Human Papilloma Virus and laryngeal tumors. It is a prospective, case control study in which a random sample of 34 patients who have laryngeal masses was included in the period between November 2017 to December 2018. The study was carried out In the Department of Otolaryngology, Basrah Teaching Hospital.

Patients were evaluated by a questioner according to gender, age, marital status, full medical history, and examination. A biopsy then was taken for histopathology study to confirm presence of tumors or other lesions. Malignant tumors were evaluated according to staging and grading systems. All lesions were examined for the presence of HPV by Immunohistochemistry (IHC) study.

The results of this study revealed that there was HPV infection in $30 \%$ of the patients. Moreover, HPV was found in $30 \%$ of laryngeal squamous cell carcinoma and in $30 \%$ of benign lesions. Statistical tests showed no significant association between HPV and Laryngeal squamous cell carcinoma.

In conclusion, although there was thirty percent of patients having HPV infections, but there was no significant association between HPV and laryngeal malignant tumours. A larger epidemiologic and more multicentric study is mandatory to evaluate the true prevalence of HPV infection in the mucosa of larynx and laryngeal malignancies.

Keywords: Human, papilloma Virus, laryngeal tumors , immunohistochemistry, laryngeal mass
\end{abstract}

\section{Introduction}

Uuman papillomavirus (HPV) infection is a sexually transmitted infection that is responsible for a growing subdivision of head and neck squamous cell carcinomas (HNSCCs). Failure to clear the virus leads to unregulated cell proliferation, more mutations, and cancer formation. While the different HPV proteins contribute to viral replication, the E6 and E7 viral oncoproteins are crucial in malignant transformation. Together they can lead to epithelial cell immortalization. E6 binds to p53 and promotes its degradation via ubiquitindependent protease pathways ${ }^{1}$. The wildtype p53 is usually activated by DNA damage or cellular stress and acts as a tumour suppressor. P53 also modulates cell cycle and regulates apoptosis ${ }^{2}$. E6 activates the hTERT promoter inducing telomerase activity, which also leads to cell immortalization ${ }^{3}$.

The E7 viral protein binds and inactivates $\mathrm{pRb}$ (retinoblastoma protein) which is an important tumour suppressor. $\mathrm{pRb}$ blocks cell cycle progression by binding to E2F transcription factor and therefore blocking progression from $\mathrm{Gl}$ to S-phase ${ }^{4}$. Therefore disruption of $\mathrm{pRb}$ E2F complex leads to unregulated cell cycle entry into S-phase leading to increased cell proliferation. Usually, 
unregulated S-phase would cause apoptosis via the p53 pathway. However, suppression of p53 activity by E6 interrupts this pathway and prevents cell death. Consequently, affected cells lose their ability to repair DNA damage then accumulate mutations and chromosomal instability. This can eventually lead to cancer formation.

Transmission of HPV; While sexual behaviours and HPV infection have been strongly linked with tumours of the oropharynx, there is little epidemiological evidence linking these with tumours of the larynx $x^{5,6}$.

The HPV infection can access basal and parabasal cells of multilayered epithelium in three different sites ${ }^{7}$ which are sites of mucosal injury, metaplastic epithelium and the squamocolumnar junction. When the HPV virus infects an active epithelial cell, it may cause a latent infection with viral replication connected with the cell cycle ${ }^{8}$.

The proliferative process initiated by the episomal form of HPV starts at the parabasal and basal layers of squamous epithelium of the oropharynx, oral cavity, or at the reserve cell layer in the respiratory epithelium of the larynx. In the larynx, the proliferation of the reserve cell (basal layer) which induced by HPV develops an alteration with a multilayered squamous cell epithelium formation and eventually papilloma can develop ${ }^{7}$.

Clinically, papillomas tends to arise from the junction of respiratory and squamous epithelium and areas of iatrogenic induced squamous metaplasia 9 .

The genital HPVs are divided into highrisk and low-risk types based on their association with invasive cervical cancer. By definition, HPV is low risk if it has never been isolated from cervical carcinoma and high risk if it ever has been. Persistent infection with any one of about 15 high-risk (carcinogenic) types accounts for virtually all cervical cancers $^{10}$. Examples of low-risk HPV: 6, 11, 42, 43, 44, 53, 54, 57, 66. High-risk
HPV: 16, 18, 31, 33, 35, 39, 45, 51, 52, $56,58,59,68^{11}$

\section{Patients and methods}

This prospective case control study included 34 patients presented with laryngeal masses attended to the otolaryngology Department, Basrah Teaching Hospital in the period between November 2017 to December 2018.

Inclusion criteria: Patients with hoarseness who do not respond to medical treatment, and patients with suspected malignant lesions through history and clinical examination.

Exclusion criteria; Patients refusing examination and endoscopy, patients who refuse to consent to the study, patients with laryngeal invasion from other primary sites such as thyroid and hypopharynx.

Patient evaluation

A complete history is taken from the patients. A complete general and full otorhinolaryngology examination was done. Flexible nasoendoscopy and 90degree rigid laryngoscopy were done using (ENTERMED diagnostic unit). All examinations were photographed. Assessment of the lesion size, location, overlying mucosa and status of surrounding tissue was done; also examination of supraglottic with epiglottis, the status of vocal folds, subglottic examination and pyriform fossae was done.

Suspected lesions such as exophytic, fungating and ulcerative lesions sent for larynx-computed tomography to assess the extent of the lesion, cartilage erosion, nodal status, and adjacent tissue involvement.

Direct laryngoscopy was done; a therapeutic excision, such as in the cases with laryngeal polyps, and biopsy taking in suspected malignant lesions.

Sections were stained using hematoxyline and eosin stain and examined under a light microscope for histopathological diagnosis. Lesions 
diagnosed as tumours, were evaluated and classified by WHO classification of laryngeal tumours ${ }^{12}$.

Immunohistochemistry study was done using a special kit Dako ${ }^{\circledR}$ Monoclonal Mouse Anti-Human Papillomavirus (HPV) Clone K1H8. Code M3528. Immunogen Alkaline disrupted HPV type $1^{13}$.

Anti-HPV antibody used in our study was found to be immunoreactive with paraffin sections of formalin-fixed HPVinfected tissues with HPV type 6, 11, 16, 18, 31, 33, 42, 51, 52, 56 and 58. Positive immunostaining was primarily confined to the nuclei of infected cells ${ }^{14,15}$.

Under general anaesthesia, direct laryngoscopy was done. After visualizing the lesions, the pathology was evaluated about site, size, type, invasion and involvement of the surrounding tissue. Excision of a mass was done. Biopsy was saved in formalin container, labelled and sent for histopathology study and Immunohistochemestry. Sections were stained using hematoxyline and eosin following the procedure of Avwioro ${ }^{16}$. Immunohistochemistry procedure; Slide preparation: removal of paraffin, rehydration, and unmasking of antigen.
After that, inactivation of endogenous peroxidase was done.

Primary antibody reaction: The slides were allowed to drain and shacked off excess fluid with a brisk motion, then primary antibody solution was applied to the appropriate slides covering the tissue sections. Secondary antibody reaction (Biotin/Streptavidin Detection) using 100 $\mu 1$ of biotinylated applied to each slide.

Substrate preparation: $20 \mu 1$ from DAB chromogen was added to each $1 \mathrm{ml}$ of substrate buffer. Counterstaining by Mayer's hematoxyline was applied to cover the section.

\section{Results}

The study comprised 34 patients. Thirty one males and three females. Data analysis was done using IBM SPSS Statistics Data Editor V.23.

Human papilloma virus immunohistochemistry was studied and showed that ten patients $(29.4 \%)$ were positive, five patients were diagnosed as having benign lesions and the other five patients were diagnosed as malignant lesions. Twenty four patients $(70.6 \%)$ were negative as shown in figures 1,2 and 3 and Table I.

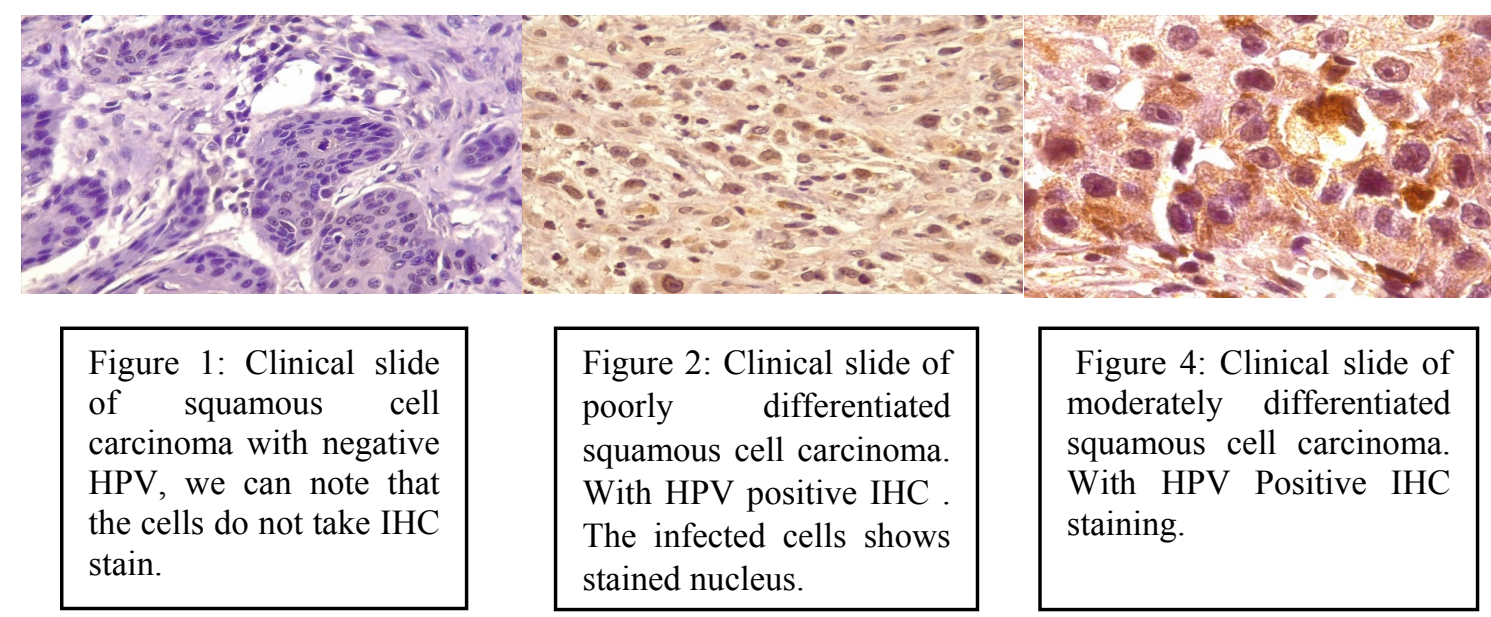


Table I: HPV immunohistochemistry staining

\begin{tabular}{|l|l|l|}
\hline & Number & Percentage \\
\hline Positive & 10 & 29.4 \\
\hline Negative & 24 & 70.6 \\
\hline Total & 34 & 100.0 \\
\hline
\end{tabular}

Because the study was based on HPV which is considered as a sexual transmitted disease, it is critical to mention that revealed that $95 \%$ of the patients were married and two patients were widows. According to lifetime sexual partners, 17 patient has one partner, 10 patients had two partners and seven patients more than two sexual partners. There is no significant association between marital status and number of sexual partners and HPV. Twenty-nine patients (85\%) were smokers, whereas five patients were nonsmokers $(15 \%)$. There was no significant relation between smoking history and HPV infection.

The masses were divided to benign and malignant lesions according to histopathology study that showed benign lesions in seventeen patients $(50 \%)$, the other seventeen patients $(50 \%)$ showed malignant growth. There was equal distribution of HVP infected cases $(50 \%$ each) and there was no statistical significant association between HPV and tumour behaviour.

According to histopathology diagnosis, squamous cell carcinoma was found in seventeen patients $(50 \%)$, a laryngeal polyp in fifteen patients $(44 \%)$ and laryngeal papilloma in two patients (6\%). Histopathology study and HPV association is studied and found that five patients out of 17 patients diagnosed as squamous cell carcinoma have HPV infection. Four patients out of 15 patients diagnosed of laryngeal polyps are HPV positive and one patient out of two patients diagnosed as papillomas has HPV infection. There was no significant relation between HPV and histopathology diagnosis as shown in table II.

Table II: Histopathological study and HPV.

\begin{tabular}{|l|l|l|l|l|l|l|}
\hline \multicolumn{9}{|c|}{} & Number & Percent & $\begin{array}{l}\text { HPV } \\
\text { Positive }\end{array}$ & $\begin{array}{l}\text { HPV } \\
\text { Percent }\end{array}$ & P-Value \\
\hline \multirow{3}{*}{ Behaviour } & benign & 17 & $50 \%$ & 5 & $50 \%$ & \\
\cline { 2 - 8 } & malignant & 17 & $50 \%$ & 5 & $50 \%$ & \\
\hline \multirow{3}{*}{$\begin{array}{l}\text { Histopathology } \\
\text { diagnosis }\end{array}$} & Polyp & 15 & $44.1 \%$ & 4 & $40 \%$ & \\
\cline { 2 - 8 } & Papilloma & 2 & $5.9 \%$ & 1 & $10 \%$ & \\
\cline { 2 - 8 } & Sq. cell Ca & 17 & $50 \%$ & 5 & $50 \%$ & \\
\hline
\end{tabular}

According to primary tissue status, seventeen patients out of thirty four were diagnosed as squamous cell carcinoma, five patients out of seventeen who have squamous cell carcinoma presented with T1 (30\%), eight patients presented with T2 (47.1\%) and two patients (12\%) presented with $\mathrm{T} 3$ and $\mathrm{T} 4$.

HPV in patient diagnosed as squamous cell carcinoma was found in one of four patients diagnosed as $\mathrm{T} 1$, Three patients out of five patients were diagnosed as T2 and one of two patients diagnosed as T4 has HPV positive infection. Statistical tests show no significant relation between HPV and tissue status of squamous cell carcinoma.

The node status was also evaluated, fifteen patients out of seventeen patients who were diagnosed as squamous cell 
carcinoma (88\%) presented with no nodal metastasis, and one patient (6\%) presented with N1 and N2. Three out of fifteen patients with no nodal metastasis have HPV positive (20\%). The remaining two HPV positive patients were N1 and N2. Statistical tests was done and show no significant relation between HPV and nodal status.

Grading of malignant samples $(n=17)$ was documented as moderately differentiated carcinoma in 11 patients $(64.7 \%)$, poorly differentiated and well differentiated in 3 patients for each $(17.6 \%)$.

Grading of squamous cell carcinoma and
HPV was studies and showed that one patients with HPV positive infection was well differentiated and two patients were moderately and poorly differentiated, respectively. Statistical test was done and show no significant relation between HPV and grade of squamous cell carcinoma.

Association between HPV and staging of malignant lesions was done and showed that $20 \%$ of HPV positive cases was on stage one, where as $40 \%$ of HPV presented with stage two. Statistical test was done and show no significant relation between HPV and stage of squamous cell carcinoma as demonstrated in Table III.

Table III: Squamous cell carcinoma and HPV

\begin{tabular}{|c|c|c|c|c|c|c|}
\hline & \multirow[t]{2}{*}{ Number } & \multirow[t]{2}{*}{ Percent } & \multirow[t]{2}{*}{$\begin{array}{l}\text { HPV } \\
\text { Positive }\end{array}$} & \multirow[t]{2}{*}{$\begin{array}{l}\text { HPV } \\
\text { Percent }\end{array}$} & \multirow{2}{*}{$\begin{array}{l}\mathrm{P} \\
\text { Value } \\
1.00\end{array}$} \\
\hline $\begin{array}{l}\text { Tissue } \\
\text { Status }\end{array}$ & & & & & & \\
\hline & T1 & 5 & $29.4 \%$ & 1 & $20 \%$ & \\
\hline & $\mathrm{T} 2$ & 8 & $47.1 \%$ & 3 & $60 \%$ & \\
\hline & T3 & 2 & $11.8 \%$ & 0 & $0 \%$ & \\
\hline & $\mathrm{T} 4$ & 2 & $11.8 \%$ & 1 & $20 \%$ & \\
\hline \multirow[t]{4}{*}{$\begin{array}{l}\text { Nodal } \\
\text { Status } \\
\end{array}$} & & & & & & 0.083 \\
\hline & N0 & 15 & $88.2 \%$ & 3 & $60 \%$ & \\
\hline & N1 & 1 & $5 . \%$ & 1 & $20 \%$ & \\
\hline & N2 & 1 & $5.9 \%$ & 1 & $20 \%$ & \\
\hline \multirow[t]{5}{*}{ Grading } & & & & & & 0.442 \\
\hline & Well differentiated & 3 & $17.6 \%$ & 1 & $20 \%$ & \\
\hline & Moderately differentiated & 11 & $64.7 \%$ & 2 & $40 \%$ & \\
\hline & Poorly differentiated & 3 & $17.6 \%$ & 2 & $40 \%$ & \\
\hline & Undifferentiated & 0 & $0 \%$ & & $0 \%$ & \\
\hline \multirow[t]{4}{*}{$\begin{array}{l}\text { Stage } \\
\text { of SCC }\end{array}$} & & & & & & 0.383 \\
\hline & 1 & 5 & $29.4 \%$ & 1 & $20 \%$ & \\
\hline & 2 & 7 & $41.2 \%$ & 2 & $40 \%$ & \\
\hline & 3 & 2 & $11.8 \%$ & 0 & $0 \%$ & \\
\hline
\end{tabular}

\section{Discussion}

This study screened three low-risk types which may cause benign lesions such as papillomatosis ${ }^{17}$. Laryngeal Papillomatosis is the most prevalent benign tumour of the larynx in children, and mother-tochild transmission is probably involved in juvenile-onset papillomatosis ${ }^{18}$. Low risk genotypes screened in the study: HPV type 6,11 , and 42 .

Eight high-risk genotypes including HPV 16 which is the most frequently detected type in laryngeal carcinomas ${ }^{19}$. High-risk 
genotypes screened in the study: HPV type $16,18,31,33,51,52,56$ and 58 .

About the relation between HPV and smoking, $90 \%$ of positive HPV were smokers, although in another study there were similar proportions of patients with HPV positive and negative tumours reported a history of cigarette smoking $(82 \% \text { vs. } 95 \% \text {, respectively })^{20}$, this may due the unequal smoking distribution in the sample $(76.5 \%$ of patients were smokers).

According to the site and side of the lesion, there was no significant association with HPV positivity, and the predominant glottic lesions $(70 \%)$ in HPV positive samples may be due to more glottic samples (79.5\%) compared with supraglottic lesion (14.7\%). Moreover, this may refer to early presentation of glottic lesions compared with other surgical sites.

We found that about $30 \%$ of the cases $(10$ out 34 patients) were HPV positive. This can be divided according to histopathological study to three groups; First group contains patients diagnosed as laryngeal polyps which conserved a normal mucosa contains no neoplastic growth, there were four patients $(26.7 \%)$ out of fourteen patients diagnosed as laryngeal polyps have HPV infected mucosa. This agree with other study that show that HPV DNA is also detected in normal mucosa (incidence:20\%) and laryngeal $\mathrm{SCCs}^{18}$. This result was approximately the same result as in Nunez et $\mathrm{al}^{21}$ which showed that postmortem specimens of macroscopically normal laryngeal mucosa were HPV positive in $25 \%$ of cases. Another study show a wide range of values of HPV in normal oral cavity mucosa, from $0 \%{ }^{22-24}$ up to $70 \%{ }^{25}$. This variation in results may be due to the effect of different methods of sample collection (PCR, Western blotting or IHC), due to the anatomic sites of sample collection (base of tongue, hypopharynx or elsewhere), and the sensitivity of the technique been used.
Other study showed vocal cord nodules and polyps have harboured HPV type 6 or HPV type 11 DNA in $23 \%$ of patients ${ }^{26}$. This goes with our result that shows $26.7 \%$ of patients with laryngeal polyps were HPV positive.

The second group is patients who were diagnosed as laryngeal papilloma which is caused primarily by HPVs 6 and 11, with a small fraction (less than 5\%) caused by HPV16 or other types ${ }^{27}$.

The third group is patients diagnosed as malignant lesions which is squamous cell carcinoma. In $29.4 \%$ of patients diagnosed as squamous cell carcinoma there is HPV infected laryngeal mucosa. In spite of this high proportion but there is no significant association between the two.

There are multiple studies about the association between the HPV and laryngeal SCC. The role of HPV infection in laryngeal cancers has been supported by many other studies but does not have strong association as that identified with cancer of the oropharynx and oral cavity $^{28,29}$.

Another Systematic Review and MetaAnalysis by $\mathrm{Li} X$ et al shows that prevalence of HPV infection in laryngeal cancer was found to be cancer in $28.0 \%{ }^{30}$. Moreover, a systematic review of articles published up to 2004 confirmed that the prevalence of HPV in SCC of the larynx could be as high as $46.9 \%{ }^{31}$.

On the other hand, In 2005, a total of 5046 head and neck cancers were pooled in a meta-analysis ${ }^{32}$; of these, 1435 were laryngeal cancers. HPV DNA was identified in $24 \%$ of tested laryngeal tumours.

A recent systematic literature review identified more than 40 publications in which laryngeal SCC was examined for the presence of HPV DNA, and found the prevalence of HPV DNA in 1,712 cases of laryngeal SCC to be $23.6 \%{ }^{33}$ which was higher than the weighted prevalence of HPV DNA in oral cavity SCC, which was $20.2 \%{ }^{33}$. 
According to the pathology grading and staging, our study reveals that there are no significant relations. This goes with other larger study which showed the same results $^{34}$.

Conclusions: This study shows that about $30 \%$ of all laryngeal masses have Human Papilloma Virus infections. About 26\% of non-neoplastic lesions presented as laryngeal polyps have HPV positive immunohistochemistry staining. We found that about one third of patients diagnosed as laryngeal malignancy as squamous cell carcinoma have HPV infected cells. In spite of these high percentages, the statistical tests shows that no significant relations present between HPV and laryngeal malignancies. The main withdrawals of this study are the small sample size, a short period that lacks prolonged followup of HPV positive patients to evaluate the prognosis of the disease, and limitation of facilities to screen more samples from other provenances in the country.

\section{References}

1.Scheffner M, Werness BA, Huibregtse JM, Levine AJ, Howley PM. The E6 oncoprotein encoded by human papillomavirus types 16 and 18 promotes the degradation of p53. Cell. 1990;63(6):1129-36.

2.Zilfou JT, Lowe SW. Tumor suppressive functions of p53. Cold Spring Harbor perspectives in biology. 2009:a001883.

3.Liu X, Dakic A, Zhang Y, Dai Y, Chen R, Schlegel R. HPV E6 protein interacts physically and functionally with the cellular telomerase complex. Proceedings of the National Academy of Sciences. 2009;106(44):18780-5.

4.Giacinti C, Giordano A. RB and cell cycle progression. Oncogene. 2006;25(38):5220.

5.Heck JE, Berthiller J, Vaccarella S, Winn DM, Smith EM, Shan'gina O, et al. Sexual behaviours and the risk of head and neck cancers: a pooled analysis in the International Head and Neck Cancer Epidemiology (INHANCE) consortium. International journal of epidemiology. 2009;39(1):166-81.

6.Hobbs C, Sterne J, Bailey M, Heyderman R, Birchall M, Thomas S. Human papillomavirus and head and neck cancer: a systematic review and meta-analysis. Clinical Otolaryngology. 2006;31(4):259-66.

7.Torrente MC, Rodrigo JP, Haigentz M, Dikkers FG, Rinaldo A, Takes RP, et al. Human papillomavirus infections in laryngeal cancer. Head and neck

2011;33(4):581-6.

8.Giroglou T, Florin L, Schäfer F, Streeck RE, Sapp M. Human papillomavirus infection requires cell surface heparan sulfate. Journal of virology. 2001;75(3):1565-70.

9.Kashima H, Leventhal B, Mounts P, Hruban RH. Sites of predilection in recurrent respiratory papillomatosis. Annals of Otology, Rhinology

Laryngology. 1993;102(8):580-3.

10.Schiffman M, Castle PE, Jeronimo J, Rodriguez AC, Wacholder S. Human papillomavirus and cervical cancer. The Lancet. 2007;370(9590):890-907.

11.Cibas ES, Ducatman BS. Cytology E-Book: diagnostic principles and clinical correlates: Elsevier Health Sciences; 2013.

12.Shanmugaratnam K. Histological typing of tumours of the upper respiratory tract and ear: Springer Science \& Business Media; 2012.

13.Iwasaki T, Sata T, Sugase M, Sato Y, Kurata T, Suzuki K, et al. Detection of capsid antigen of human papillomavirus (HPV) in benign lesions of female genital tract using anti-HPV monoclonal antibody. The Journal of pathology

1992;168(3):293-300.

14.Iwasaki T, Sata T, Sugase M, Sato Y, Kurata T, Suzuki K, et al. Detection of capsid antigen of human papillomavirus (HPV) in benign lesions of female genital tract using anti-HPV monoclonal antibody. The Journal of pathology. 1992;168(3):293-300. 
15.Prendiville W, Davies P. The Health Professional's HPV Handbook: Human Papillomavirus and Cervical Cancer: CRC Press; 2006.

16.Avwioro G. Histochemical uses of haematoxylin—a review. Jpcs. 2011;1:24-34.

17.Larson DA, Derkay CS. Epidemiology of recurrent respiratory papillomatosis. Apmis. 2010;118(6-7):450-4.

18. Aaltonen LM, Rihkanen H, Vaheri A. Human papillomavirus in larynx. The Laryngoscope. 2002;112(4):700-7.

19.Duray A, Descamps G, Arafa M, Decaestecker C, Remmelink M, Sirtaine N, et al. High incidence of high-risk HPV in benign and malignant lesions of the larynx. International journal of oncology. 2011;39(1):51-9.

20.Fakhry C, Westra WH, Li S, Cmelak A, Ridge JA, Pinto H, et al. Improved survival of patients with human papillomavirus-positive head and neck squamous cell carcinoma in a prospective clinical trial. Journal of the National Cancer Institute. 2008;100(4):261-9.

21.Nunez DA, Astley SM, Lewis FA, Wells M. Human papilloma viruses: a study of their prevalence in the normal larynx. The Journal of Laryngology Otology. 1994;108(4):319-20.

22.Eike A, Buchwald C, Rolighed J, Lindeberg H. Human papillomavirus (HPV) is rarely present in normal oral and nasal mucosa. Clinical Otolaryngology

Allied Sciences. 1995;20(2):171-3.

23.Bouda M, Gorgoulis VG, Kastrinakis NG, Giannoudis A, Tsoli E, Danassi-Afentaki D, et al. "High risk" HPV types are frequently detected in potentially malignant and malignant oral lesions, but not in normal oral mucosa. Modern Pathology. 2000;13(6):644.

24.Sand L, Jalouli J, Larsson P, Hirsch J. Human papilloma viruses in oral lesions. Anticancer research. 2000;20(2B):1183-8.

25.Terai M, Hashimoto K, Yoda K, Sata T. High prevalence of human papillomaviruses in the normal oral cavity of adults. Oral microbiology immunology. 1999;14(4):201-5.

26.Rihkanen H, Peltomaa J, Syrjänen S. Prevalence of human papillomavirus (HPV) DNA in vocal cords without laryngeal papillomas. Acta oto-laryngologica. 1994;114(3):348-51.

27.Abramson AL, Steinberg BM, Winkler B. Laryngeal papillomatosis: clinical, histopathologic and molecular studies. The Laryngoscope. 1987;97(6):678-85.

28.Almadori G, Galli J, Cadoni G, Bussu F, Maurizi M. Human papillomavirus infection and cyclin D1 gene amplification in laryngeal squamous cell carcinoma: biologic function and clinical significance. Head Neck: Journal for the Sciences Specialties of the Head Neck. 2002;24(6):597-604.

29.Smith EM, Summersgill KF, McCulloch T, Allen J, Turek LP, Hoffman HT, et al. Human papillomavirus and risk of laryngeal cancer. Annals of Otology, Rhinology

Laryngology. 2000;109(11):1069-76.

30.Li X, Gao L, Li H, Gao J, Yang Y, Zhou F, et al. Human papillomavirus infection and laryngeal cancer risk: a systematic review and meta-analysis. The Journal of infectious diseases. 2012;207(3):479-88.

31. Rees L, Birchall M, Bailey M, Thomas S. A systematic review of case-control studies of human papillomavirus infection in laryngeal squamous cell carcinoma. Clinical Otolaryngology Allied Sciences. 2004;29(4):301-6.

32.Kreimer AR, Clifford GM, Boyle P, Franceschi S. Human papillomavirus types in head and neck squamous cell carcinomas worldwide: a systematic review. Cancer Epidemiology Prevention Biomarkers. 2005;14(2):467-75.

33.Isayeva T, Li Y, Maswahu D, Brandwein-Gensler M. Human papillomavirus in nonoropharyngeal head and neck cancers: a systematic literature review. Head and neck pathology. 2012;6(1):104-20.

34.Güvenç MG, Midilli K, Özdoğan A, İnci E, Tahamiler R, Enver Ö: Detection of HHV-8 and HPV in laryngeal carcinoma. Auris Nasus Larynx. 2008;35(3):357-62. 